IZA DP No. 9924

The Mixture as Before? Student Responses to the Changing Content of School Meals in India

Farzana Afridi

Bidisha Barooah

Rohini Somanathan

May 2016 


\title{
The Mixture as Before? \\ Student Responses to the Changing Content of School Meals in India
}

\author{
Farzana Afridi \\ Indian Statistical Institute \\ and IZA
}

Bidisha Barooah

International Initiative for Impact Evaluation

Rohini Somanathan

Delhi School of Economics

Discussion Paper No. 9924

May 2016

IZA

P.O. Box 7240

53072 Bonn

Germany

Phone: +49-228-3894-0

Fax: +49-228-3894-180

E-mail: iza@iza.org

\begin{abstract}
Any opinions expressed here are those of the author(s) and not those of IZA. Research published in this series may include views on policy, but the institute itself takes no institutional policy positions. The IZA research network is committed to the IZA Guiding Principles of Research Integrity.

The Institute for the Study of Labor (IZA) in Bonn is a local and virtual international research center and a place of communication between science, politics and business. IZA is an independent nonprofit organization supported by Deutsche Post Foundation. The center is associated with the University of Bonn and offers a stimulating research environment through its international network, workshops and conferences, data service, project support, research visits and doctoral program. IZA engages in (i) original and internationally competitive research in all fields of labor economics, (ii) development of policy concepts, and (iii) dissemination of research results and concepts to the interested public.
\end{abstract}

IZA Discussion Papers often represent preliminary work and are circulated to encourage discussion. Citation of such a paper should account for its provisional character. A revised version may be available directly from the author. 
IZA Discussion Paper No. 9924

May 2016

\title{
ABSTRACT
}

\section{The Mixture as Before? Student Responses to the Changing Content of School Meals in India*}

\begin{abstract}
We study how attendance rates of primary school children respond to cost neutral changes in the design of India's school meal program. Municipal schools in the capital region of Delhi switched from packaged food to on-site cooked meals in 2003, with insignificant changes in the budget available per meal. We use the staggered implementation of this transition and child-level panel data to find that cooked meals resulted in a 3-4 percentage point rise in average monthly attendance with the largest effects observed for early grades. The impact on girls was especially large, but since they attend morning shift schools while boys attend the afternoon shifts, these gender effects may simply reflect benefits from better timed meals. We also find attendance gains concentrated in schools that served diverse menus. Our results suggest that even within constrained budgets, better designed school transfer programs can improve student level outcomes.
\end{abstract}

JEL Classification: D1, E31, F01

Keywords: school meals, school participation, program design

Corresponding author:

Farzana Afridi

Indian Statistical Institute

7, S.J.S. Sansanwal Marg

New Delhi - 110016

India

E-mail: fafridi@isid.ac.in

\footnotetext{
* This paper has benefitted from comments by seminar and conference participants at the Delhi School of Economics, Growth and Development Conference (ISI), UNSW Development Economics Workshop, ADB (Manila), Asian Meeting of the Econometrics Society (Delhi) and the IGC-ISI Conference (2014). The authors are responsible for any remaining errors.
} 


\section{Introduction}

School transfers have become a popular instrument for improving the educational outcomes of children. A variety of programs implemented in developing countries, such as cash transfers, scholarships, textbooks and school meals, subsidize the cost of schooling either directly or indirectly (Glewwe and Kremer, 2006). ${ }^{1}$ Many of these initiatives have improved school participation rates, especially for girls and young children, but at a relatively high cost. ${ }^{2}$ Can countries with binding budget constraints increase the benefits of these transfers through better program design? In this paper we study a fiscally-neutral transition in India's school meal program from ready-to-eat snacks to cooked meals and estimate sizable attendance gains for children in public primary schools. By combining variation in the timing and composition of these meals across schools with student-level panel data on attendance, we identify the most effective components of the new program and the types of students most responsive to it.

Three and a half million children in the world today are estimated to have access to school meals and about one third of these are in India (World Food Programme, 2013). The Indian school meal scheme has its origins in the Nutritional Support for Primary Education Program launched by the federal government in 1995. Under the program, Indian states received free transfers of food grains and were responsible for their conversion into free cooked meals in public schools. This rarely happened and most schools distributed the rations received from the federal government to children who achieved an attendance threshold. In November 2001, in a landmark judgement, the Supreme Court of India ordered all states to complete the transition to cooked meals within six months. Progress remained slow as states struggled with developing the infrastructure necessary for the functioning and monitoring of the program. The Court subsequently extended the deadline to September 2004. Municipal schools in Delhi were among the first in the country to make the transition and did so in phases during the 2003-2004 academic year. We use attendance data during this phased transition to estimate the effect of

\footnotetext{
${ }^{1}$ Conditional cash transfers through PROGRESA in Mexico improved school enrolments (Schultz, 2004) and grade attainment (Behrman et al., 2005). Distribution of free uniforms and textbooks in Kenya lead to lower drop-out rates and 15\% more schooling in treated schools (Kremer et al., 2002) and reduced school absenteeism by $34 \%$, on average (Evans et al., 2008). Scholarships to girls in Kenya showed some evidence of increase in attendance rates of girls (Kremer et al., 2009).

${ }^{2}$ Cash transfers under PROGRESA varied between 84 to 162 USD for primary and 240 to 306 USD for a secondary school student per year (@1 USD=10 pesos in 1998-2000; Schultz, 2004); free uniforms and textbooks cost USD 6 per uniform and USD 3.44 per student per year, respectively (Kremer et al., 2002); merit scholarships for girls cost USD 19.20 per student per year(Kremer et al., 2009).
} 
the cooked school meal program in Delhi.

The Indian school meal program is remarkable, both for its size and its low cost. ${ }^{3}$ During the period we study, school authorities paid approximately 2 rupees per meal, equivalent to 4.4 cents or USD 8.8 for a student in a school year in $2004 .{ }^{4}$ In Delhi, this was used to purchase packaged snacks such as biscuits and puffed wheat. With the cooked meal program, the same allocation was given to providers for the purchase of non-grain ingredients, preparation and transportation of the meal to schools. Thus, from the perspective of the state-budget, the transition was cost-neutral. ${ }^{5}$ However, with only broad guidelines set for the multiple providers servicing this area, there was substantial variation in the content of meals served within this area. Some schools received the simplest meals that consisted of single items, such as porridge, while others were served more elaborate menus by their providers. Another difference between the two regimes is the timing of the meals. We are able to specifically examine some of these elements of design.

Our dataset is assembled from attendance and administrative records of over 1500 students in 19 randomly sampled municipal schools from one of the school zones of Delhi. Our sampled schools are at most 15 kilometres apart and administered by the same nodal authority, the Municipal Corporation of Delhi (MCD). We construct a student-level panel data from administrative records on attendance and variations in the timing of the school meal program during 2003-04 academic year to estimate the immediate effect of the transition from providing packaged, ready-

\footnotetext{
${ }^{3}$ With over 120 million reported child beneficiaries per day it is now the largest school feeding program in the world, Ministry of Human Resource Development (mdm.nic.in) accessed in July, 2014.

${ }^{4}$ The average cost of running Food for Education (FFE) programs at the World Food Program in 2005 was USD 15.79 per child per year. The cost of on-site meals alone was slightly higher, whereas that of biscuits averaged USD 9 per child. For take-home rations, the annual average cost was much higher (USD 30) because of transport costs and differences in food bundles (Adelman et al., 2008). The FFE program in Bangladesh cost more than USD 25 in 1996 (Ahmed and Del Ninno, 2002).

${ }^{5}$ Providers were reimbursed at a rate of Rs. 2 per child per day for expenditures incurred on meal ingredients other than grain ( vegetables, spices), fuel, transportation and wages in 2002-04 at the same rate as the readyto-eat regime (Communication from the Ministry of Human Resource Development via letter number D-186 $\mathrm{DDE} / \mathrm{MDM}(\mathrm{HQ}) / 11)$. Thus the per child cost of the two programs was identical except a marginal difference under the ready-to-eat program, 75.6 gms. of wheat per child per day was being supplied to the packaged food provider in 2002-03 as against 100 gms. of wheat to the service provider under the cooked meal program in 200304 to meet the norm of 300 calories and 8-12 gms. of proteins per meal (Communication from the Ministry of Human Resource Development via letter number D-186 DDE/MDM(HQ)/11). This led to a marginal difference of approximately Rs. 0.11 (attributable to $24.4 \mathrm{gm}$ difference in foodgrain content), or less than $5 \%$ per child per day between the two programs (insignificant in real terms; see Table A1 in the Appendix). The cost of grains and transportation subsidy during this period remained constant at Rs. 4.2 and Rs. 0.05 per kilogram of wheat.
} 
to-eat snacks to cooked meals on the average monthly attendance of primary school students in Delhi. As mentioned above, Delhi transitioned from ready-to-eat snacks to cooked meals in phases during the 2003-2004 academic year, starting with July 2003 and attaining full coverage by April 2004. The signing of contracts with school meal providers for the preparation and delivery of the meals by the municipality were staggered over 2003. Once a provider obtained a contract, schools which were located closer to the meal provider transitioned to cooked meals before those that were located further away. Thus the timing of the phasing-in of the schools into the cooked meals program was plausibly exogenous to school characteristics. Based on this identifying assumption and using multiple observations on individual students to control for unobservable individual and school heterogeneity, we adopt a difference-in-differences strategy comparing the difference in the attendance rate of students in schools that transitioned early to those whose schools transitioned later to cooked meals between April and September 2003.

School meals - both the more portable ready-to-eat snacks or the less so, on-site cooked meals can improve daily student participation by implicitly reducing the cost of schooling. However, the effect of a cost-neutral transition to cooked meals on students' daily attendance is ambiguous. First, the magnitude of the impact on student attendance is likely to be determined by the relative incentives of the two programs for a child to attend school regularly. While a transfer that can be readily redistributed and shared within the household, such as ready-to-eat snacks, could be less attractive, a transfer that is well targeted at an individual household member, such as cooked school meals, may be provide greater incentive to that member to meet the conditionality of the transfer. On the other hand, an altruistic parent may be indifferent between the two types of programs. Thus the effect of the transition in program design could be determined by whether the parent or the child takes the daily decision to attend school. Second, the design of the school transfer program could influence program implementation and thereby the extent of benefits realized by the targeted beneficiaries. For instance, the daily distribution of cooked meals within school premises could over burden the limited resources of public schools. This may offset the program's potential positive impact on students' school participation by adversely affecting the quality of teaching (Vermeersch and Kremer, 2005). On the other hand, program leakages at the school-level could be lower when hot meals are provided relative to ready-to-eat snacks since the daily distribution of the former can be monitored more easily. This may improve the regularity of the provision of school meals, making the program more attractive for intended beneficiaries.

The existing literature has found conflicting results on the provision of more versus less portable 
school meals. Alderman et al. (2012) compare the effect of a take-home rations program conditional on minimum stipulated monthly attendance and a school feeding program of equivalent value in Uganda by randomly assigning schools to either type of school meal program and a control group that received nothing. They find that both programs improve school attendance by 8-9 percentage points, although statistically, one program was not more effective than the other. But it is difficult to evaluate the relative cost effectiveness of the two programs due to absence of information on costs. Kazianga et al. (2012) use a similar randomized design in Burkina Faso to assess the relative effectiveness of school meals, where all students are provided lunch each school day while only girls were eligible for take-home rations of $10 \mathrm{~kg}$ of cereal flour each month, conditional on attending school $90 \%$ of monthly school days. They find that the latter program led to a reduction in student absenteeism by 1 day for those children who had more siblings while the on-site lunch had no impact on absenteeism. The cost of the programs was high relative to their negligible benefits - USD 41.46 for cooked school meals and USD 51.37 per student per year for take-home rations.

In the Indian context, Afridi $(2010,2011)$ finds significant positive effects of providing cooked school meals on child nutrition and participation of girls in grade 1 in a set of villages in central India. Singh et al. (2014) using child level panel data from the state of Andhra Pradesh to study long-term health impacts of cooked school meals show that it is able to insulate child health from negative household income shocks. Jayaraman and Simroth (2015) use nation-wide panel data on schools and the staggered implementation of the cooked meals across Indian states between 2003 and 2004 to estimate the impact of the program on school enrolments. They find sizeable enrolment effects of the meals, particularly in grade 1. These findings are echoed in survey studies by Khera $(2006,2013)$ which highlight the issue of poor quality of school meals and Dreze and Goyal (2003) who document the large differences in school infrastructure and meal quality across states. ${ }^{6}$

Our study makes several significant contributions to this literature. First, we use data that track children rather than schools. Unlike existing studies on school feeding programs, which utilize either school level survey data or are small-scale randomized trials, we utilise child-level panel data using a natural experiment to study the design of a large program in a real-world

\footnotetext{
${ }^{6}$ Vermeersch and Kremer (2005) find an 8.5 percentage point increase in daily attendance for pre-school children in Kenya in a randomized study of cooked meals program. Non-randomized evaluations by Ravallion and Wodon (2000) and Ahmed (2004) of the take-home rations program in Bangladesh show higher school enrolment and daily attendance by students.
} 
scenario. Second, while almost all studies on the school meal program in India evaluate the impact on enrolments our main outcome of interest is the attendance rate of students, a more accurate measure of presence of students in schools. Third, we explicitly study the impact of design and variations in the type of school meal program within a narrowly defined geographical zone, while keeping program costs low and neutral to changes in program characteristics. To the best of our knowledge we are the first to study how variation in the timing of the meal and type of menu of school meals impacts students' participation rates.

We find an average increase in attendance rates of 3-4 percentage points in response to the transition to cooked meals. This effect however varies by grade, menu composition and the timing of the meal. The largest effects are seen for young children, diverse menus and schools that operate in the morning as opposed to afternoon shifts. We observe no effects for grade 5 while children in grade 2 experience a 7 percentage point increase in average monthly attendance. We find that attendance gains were concentrated in schools where meals consisted of multiple items with pulses or vegetables provided in addition to cereals. Most of the only-boys schools in our samples operate in the afternoon shift, in the same building occupied by a girls-only school in the morning. This makes it difficult to disentangle gender effects from those related to meal timing. However, we find statistically significant effects of the cooked meals only in the morning schools. There are no gender differences in program effects when we limit our sample to the morning shift but these results are based on small samples for boys and need to be interpreted with caution.

Although school participation has been steadily expanding in India, acceptable levels of daily school attendance by students have remained elusive. ${ }^{7}$ Our results suggest that the transition from ready-to-eat snacks to cooked meals made the meal program more attractive to students thereby improving their daily attendance in schools significantly in Delhi. While we are unable to identify the precise mechanism through which program transition impacted student participation rates, we show that the quality of meals matter. In addition, we conjecture that improved targeting due to the less portable cooked meals, increase in the regularity of the provision of meals or just greater attractiveness of a hot meal influenced daily attendance levels relative

\footnotetext{
${ }^{7}$ Between 1951 and 2011, there was a steady increase in enrolment rates to over $90 \%$ for primary school aged children (Government of India, 2013). Yet, about a quarter of children enrolled in primary grades dropout before the end of their academic year (http://data.worldbank.org/indicator/SE.PRM.NENR). Unannounced visits to a nationally representative sample of schools found that only $68 \%$ of enrolled students were in attendance (Educational Consultants India Limited, 2007).
} 
to the ready-to-eat regime. ${ }^{8}$ Our findings, thus, show that merely modifying the design of an existing program could lead to significantly higher program benefits. This is especially relevant in budget-constrained developing countries.

The remainder of the paper is organized as follows: Section 2 provides a conceptual framework which forms the basis of our empirical approach. Section 3 discusses the data and estimation strategy. The results are presented in section 4 while section 5 concludes.

\section{Conceptual Framework}

A child's daily attendance depends on the benefits relative to the costs of her being in school. The cost of attending school includes the direct costs, such as those related to transportation, and the opportunity cost of time that could have been spent on either working at home or for wages or both. The benefits of school attendance are derived from the present value of future earnings from learning in school as well as transfers received in school which are conditional on regular attendance such as school meals (cooked or ready-to-eat).

The benefits from the meal program could vary between the ready-to-eat and cooked meals regime for various reasons. First, the portability of the transfer could determine a child's daily school attendance. In the more portable ready-to-eat regime, the household may perceive the transfer as additional income for the entire household which can be redistributed amongst members or siblings of the intended beneficiary. On the other hand, the provision of hot, cooked meals on the school premises, which is more likely to be consumed within school hours, may incentivize the child to attend school more regularly while lowering the incentive of the household to send the child to school relative to the ready-to-eat regime. Thus a change in the type of the transfer could affect daily school attendance depending on how the incentives of the child relative to the parent are affected.

\footnotetext{
${ }^{8}$ An evaluation of the school meal program in Delhi by the Nutrition Foundation of India reports that, before the cooked meal program, packaged snacks were distributed on only 50 days in a school year on average, although the national policy mandated 200 days (Sharma et al., 2006). In contrast, cooked school meals were served for 150-200 days in a school year, based on our data. This may have increased the total monthly value of the meal to the child and therefore, the incentive to attend school.
} 
Second, the benefits derived from learning in school could vary depending on the type of meal transfer on two counts - by directly affecting the child's cognition and indirectly through its impact on school quality. Both ready-to-eat and cooked meals could improve a child's learning outcome by reducing hunger and thereby improving attention in the classroom if both types of meals are consumed during school hours. This is more likely to be the case with the cooked meals regime since these meals are served hot on the school premises. However, the transfer program also puts a strain on the limited resources of the public schools because the distribution of meals during school hours can reduce instruction time, cause disruption and burden the school management. School resources are more likely to be strained by the cooked meals vis-a-vis readyto-eat meals since distributing hot meals daily requires greater organizational and management skills. Hence the net learning benefits from cooked meals could be potentially lower than from the ready-to-eat regime if the quality of schooling is adversely impacted by the former.

Finally, there exist concerns about substantial leakages of transfers from targeted beneficiaries, particularly in a developing country setting. Even if both types of meal program are mandated on all school days, the ready-to-eat meals are potentially more susceptible to pilferage and diversion if they are typically dry items such as biscuits. In contrast, the distribution of cooked meals can be monitored more easily because it is relatively easy to observe whether children were served hot meals or not. If the regularity of the program is better under the cooked regime then both parental and child incentives to attend school more regularly will be higher than under the ready-to-eat regime.

In addition to the above causes of variation in benefits due to changes in program design, there could be heterogeneity in both the perceived benefits of the two transfer programs and costs of schooling by gender, age and other child, household and school characteristics. Thus, the overall impact of a transition in the school meal program from the ready-to-eat cooked meals regime on school attendance is ambiguous.

More formally, suppose a child $i$ 's cost of attending school in any given month is normally distributed according to $F_{i}(c)$ with density $f_{i}(c)$. Let $b_{i}$ denote the child specific benefits from attending school including benefits from school transfers. The monthly attendance for child $i$ is $F_{i}\left(b_{i}\right)$. Now suppose there is a change in the design of an existing school transfer program which changes the benefits from attending school. In our case, this change would be the switch from ready-to-eat snacks to cooked meals. The benefits of schooling changes from $b_{i 0}$ to $b_{i 1}$ while all 
children face similar costs of schooling as shown in Figure 1a.Then, the change in attendance is $F_{i}\left(b_{i 1}\right)-F_{i}\left(b_{i 0}\right) \cdot{ }^{9}$ Attendance is positively impacted since $\Delta b_{i}>0$ as shown by the dark shaded area in Figure 1a. This is the treatment effect of program transition that we are interested in. However, if the benefits from schooling, following program transition is $b_{i 1}^{\prime}$ then $\Delta b_{i}<0$ in Figure 1a. On the other hand, if all children value the change in school benefits similarly such that $\Delta b_{i}$ is comparable across all $i$ but the cost of schooling varies between children, the effect of the program transition on school attendance would be higher for children with larger costs of schooling if the initial level of attendance is high or $f_{i}^{\prime}<0$ as illustrated in Figure $1 b .{ }^{10}$ In reality, both the cost of schooling and the change in benefits due to program transition could vary. Hence the treatment effect due to program transition can differ in magnitude as well as direction across children.

We estimate the change in the monthly attendance rate of child empirically as a function of the change in benefits due to the transition in meal program conditional on individual, household and school characteristics. Multiple observations for the same child allow us to account for unobservable individual characteristics which also absorb time invariant household and school characteristics, such as parental preferences and school quality. The treatment effect we estimate then is an average of potentially heterogeneous effects of program transition. We discuss our data and identification strategy in detail next.

\section{Data and Estimation Strategy}

\subsection{Data}

Public primary schools in Delhi are administered by three agencies: the Municipal Corporation of Delhi (MCD), the New Delhi Municipal Corporation (NDMC) and the Directorate of Education. ${ }^{11}$ Over three-quarters (approximately 1800) of all primary schools in the city fall

\footnotetext{
${ }^{9}$ For small benefits, the change in attendance can be approximated by $\Delta b_{i} * f_{i}$ where $\Delta b_{i}=b_{i 1}-b_{i 0}$ and $f_{i}$ denotes the value of the density function at $b_{i 0}$.

${ }^{10}$ Note that if $f_{i}^{\prime}>0$ or the initial level of attendance is low then the effect would be smaller for children with higher costs of schooling.

${ }^{11}$ In 2011, much after this study, the MCD was split into three separate bodies - North, South and East Delhi Municipal Corporations. Our data come from municipalities which are currently administered by the South
} 
within the purview of the MCD, across 12 administrative zones. These schools are perceived to be of lower quality and have the highest proportion of students from slums and disadvantaged communities (De et al., 2005). Our data come from schools in one of the 12 MCD zones of Delhi, the central zone, enabling us to study a constrained geographic area with multiple school meal providers. This allows us some heterogeneity in school meal menus and yet limits the variation in the characteristics of households served by the schools we study. ${ }^{12}$

Students in the MCD schools first started receiving "meals" in 1997, but these were mainly packets of biscuits which were not distributed every school day as mandated under the meal program. In order to comply with a Supreme Court order, the MCD invited private parties to express interest in providing cooked meals in January 2003. Contracts were initially signed with 35 providers to supply meals to 410 MCD schools. The program was extended in September 2003 and all MCD schools were reportedly covered by April 2004. ${ }^{13}$. This resulted in plausibly exogenous staggering of the transition from ready-to-eat to cooked meals across schools - schools which were located relatively closer to a provider transitioned to cooked meals earlier than those located farther away. ${ }^{14}$ We are interested in identifying the immediate student participation impacts due to the transition in the meal program from ready-to-eat to cooked meals and from the variation in the design of the program, viz. meal timings and menu type, immediately following this transition. The focus of our analysis, therefore, is on the academic years of 2002 and $2003 .^{15}$

We use three sources of school level data in our analyses: first, student attendance records maintained by the MCD schools for the academic years 2002 to 2003. If a school had multiple sections at a particular grade level, we randomly selected one section for which we requested attendance registers. Our second source of data is the school meal register, which records the menu offered on all school days. This is required by the MCD because cooked meal providers were compensated based on average daily attendance. These records enable us to identify the

Delhi Municipal Corporation.

${ }^{12}$ Table A2 in the Appendix indicates that the demographic characteristics of the central zone of the MCD are comparable to the average characteristics of urban Delhi.

${ }^{13}$ The ready-to-eat snacks provided under the program primarily consisted of biscuits and occasionally rice/wheat puffs or roasted pulses. The meals in the cooked regime consisted of either two item menus such as rice/wheat bread with pulses/vegetables or single item menus such as salty or sweet porridge.

${ }^{14}$ The average distance of schools from their providers in 2003 for our original sample of 22 schools was 4.8 kilometres. Providers were located at a distance of 4.3 kilometres from schools that transitioned early and 5.3 kilometres from schools that transitioned later to cooked meals.

${ }^{15}$ A typical academic year runs from April to March and consists of approximately 200 school days. 
exact date each school transitioned to cooked meals. We entered school participation data for one calendar month before and after the introduction of the cooked meal to allow us to relate changes in enrolment to menu offered. Finally, in addition to these administrative records, we collected retrospective survey data on the school's infrastructure in 2003 through interviews with the school headmasters.

At the time we began our data collection in January 2008, there were three different meal providers in the central zone. In addition to the list of providers and the location of their kitchens, the MCD administration provided us with lists of schools served by each of these providers and we selected a random sample of 8 schools from each of the three lists, giving us with a total sample of 24 schools. Obtaining complete student records for all academic years of our research interest proved difficult because schools are required to maintain records for up to 5 years only. ${ }^{16}$ We could not obtain attendance records for any of the academic years of research interest for 2 of the 24 schools. Of the remaining 22, we could obtain attendance records for both 2002 and 2003 for 19 schools. Our main sample, therefore, consists of 19 schools. ${ }^{17}$

By September 2003 all children in about half the schools in our sample had access to the cooked meals (Phase 1) while the other half continued to receive packaged snacks (Phase 2). ${ }^{18} 9$ of our 19 schools are in the Phase 1 group by this criterion. Table 1 shows the descriptive statistics of the 19 schools, by phase, computed at the MCD ward (by matching schools to the wards in which they were located and using census data for 2001) and school level. ${ }^{19}$ The table suggests that, on average, the wards that the two school groups catered to were comparable on demographic characteristics. Average school level monthly attendance rates in April 2003 in both school groups was similar but high relative to the national average (Educational Consultants India Limited, 2007). Even though the distance to the meal provider was not significantly different, Phase 2 schools were further away from their provider than Phase 1 schools. $t$ tests of the differences in school infrastructure between the two groups of schools indicate that the two

\footnotetext{
${ }^{16}$ For the year 2002, we collated data for each student in a grade for the months April, July, September and February, which coincide with the beginning, middle and end of an academic year in MCD schools, respectively. For the year 2003, we were able to obtain student records for all school months.

${ }^{17}$ See the geographical distribution of the 19 sampled schools in Figure A1 in the Appendix. We do not find any systematic differences in school level characteristics of the 19 schools for which we obtained data and the 5 schools for which school records were missing.

${ }^{18}$ Uptake of the program was near universal during our survey in 2008 . In a random sample of 571 students in our sampled schools, $94.2 \%$ had consumed the cooked school meal on the day of our school visit.

${ }^{19}$ Each MCD zone is further subdivided into wards for administrative purposes. There are a total of $272 \mathrm{MCD}$ wards.
} 
groups are comparable to each other, at least on observables.

\subsection{Empirical Strategy}

To identify the impact of program transition on students' school participation, we utilize the staggered implementation of cooked meals from ready-to-eat snacks. Phase 1 schools in our sample implemented cooked meals in July and August 2003 while Phase 2 schools did so in October and November 2003. Thus, the former form the treatment group while the latter the control - we compare the change in average attendance rates between April and September 2003 of Phase 1 and Phase 2 schools. Our main estimating equation, therefore, is given by

$$
A_{i j}=\alpha_{0}+\alpha_{1} m+\alpha_{2} \text { Treat }_{j} * m+\mu_{i}+\epsilon_{i j}
$$

where $A_{i j}$ is the attendance of child $i$ in school $j$. Attendance is defined as the number of days a child attends school in a month over the total number of school days in that month. Treat is an indicator for treatment school ( $=1$ for schools which transitioned to cooked meals before September, 2003) and $m$ is an indicator for month (=1 for September 2003). Our base month is April 2003.

Even though the differences in treatment and control schools are not statistically significant (Table 1), the small sample size necessitates caution. Thus our preferred specification of the effect of the meal program on average monthly attendance is to allow for child, household and school characteristics to influence the rate of attendance. The identifying assumption is that once we account for variation in these characteristics, they do not affect attendance rate changes over the school year. Unobservable, time-invariant child-characteristics, which also absorb time invariant household and school characteristics, are included in the specification and denoted by $\mu_{i} . \epsilon_{i j}$ is the idiosyncratic error term. The main coefficient of interest is $\alpha_{2}$ which gives the difference-in-difference (DID) estimate of the impact of the transition in the school meal program. 
Although phased implementation allows us to classify schools into treatment and control groups, we cannot be certain that the selection of schools to either group is random. Unobservable, time varying school-level characteristics may have influenced program transition timing as well as any observed changes in attendance rates of students. We address this concern by looking at the change in attendance rates between April and September 2002 of cohorts in the same grades of the same schools in 2002. To do so we restrict our sample to equivalent grades in 2002 and 2003 in our sample of 19 schools. Thus, we construct a repeated cross-section of school and grade by year. Analyzing data for 2002 allows us a more stringent test of our program effect if we find significantly larger attendance changes in treatment schools over the 2002 academic year relative to the control schools before the program was initiated, it is likely that some of the program effect we estimate in 2003 is driven by different attendance trends for schools in the treated and control sample.

Since the academic year in all government schools runs from April to March, children in our data are observed in the same grade and classroom in the months of April and September. Most new grade 1 students enrol into school in the first month of the academic year -April- while others enrol by August. Attendance rates for April are usually difficult to compute for a grade 1 child because we often do not know the exact date at which the child enrolled in the school while the majority of students of higher grades (or those repeating grade 1) continue to be enrolled from the previous academic year. To avoid measurement errors, therefore, we restrict our analysis to grades 2 through $5 .^{20}$

\section{Results}

\subsection{Effect of transition to cooked meals on attendance rates}

Table 2 shows the average school level change in attendance rates between April and September for the years 2002 and 2003. Prior to the introduction of cooked meals, in April 2002, the average attendance rate in treatment schools was insignificantly lower but both treatment and control schools had an equivalent increase in the attendance rate between April and September

\footnotetext{
${ }^{20}$ Inclusion of grade 1 in our data does not change our results. These results are available on request.
} 
2002 (0.06). Between April and September 2003, control schools gained as much as the previous year (0.07) while treatment schools, which had made the transition to cooked meals, had a significantly larger increase in attendance rate (0.11). The additional gain of 4 percentage points made by the treatment schools in 2003 provides us with a suggestive estimate of the effect of transition in the design of the school meal program.

We now turn to our regression analysis to establish causal links between the program and attendance rates using alternative specifications and samples to estimate average program effects using equation 1 . In columns 1 and 2 of Table 3 we restrict our sample to include only those grades of the main sample of 19 schools for which we have attendance data in both 2002 and 2003 in order to examine whether the observed treatment effect is simply capturing differences in attendance trends across these two sets of schools. This gives us a sample size of 1591 and 1564 students in 2003 and 2002 respectively. From column 1 we find a significant increase of 2.7 percentage points in average student attendance rates due to the transition to cooked meals in 2003. Column 2 provides us with placebo tests by estimating equation 1 using the corresponding samples in columns 1, but with the attendance rates of 2002 as the dependent variable rather than in 2003. As expected, the difference-in difference coefficient is insignificant suggesting that the change in attendance of treatment schools did not differ from control schools before the program came into effect.

One could argue that comparing attendance trends of cohorts in similar grades may lead to biased estimates if students in these cohorts are systematically different. Our results would be robust if we find that the same students had identical attendance trends in 2002 but this changed after they got meals in 2003. To do this, we construct a student-level panel by matching attendance records of the relevant grades in 2002 and 2003. For instance, we matched attendance records of grade 2, section A of a school in 2002 and grade 3, section A of the same school in 2003, conditional on us having obtained attendance records for both grades and years. Each student is identified by a unique enrolment number assigned to her at the time she is admitted into the school. Since students rarely switch sections we were able to track almost all students by following the same grade-section over the sampled years. However, we lose 3 schools in this panel for which we could not obtain the attendance records of the relevant grades in 2002 . Thus column 3 shows estimates from equation 1 but restricts the sample to a balanced panel of 827 students who were enrolled through April 2002 to September 2003. The coefficient on the difference-in-difference term (3.1 percentage points) is remarkably similar to the estimated effect in column 1. For the same students, we do not see any difference in attendance trends in 
2002 (column 4). Hence the impacts we measured in columns 1 and 3 are indeed attributable to the transition in the program to cooked meals.

\title{
4.2 Heterogeneity of impact
}

\author{
Grade, gender and meal timing
}

The estimated average program effect may be hiding significant heterogeneity of effects by grade, gender as well as characteristics related to the design of the program.

We first estimate the transition impacts by grade by restricting our sample to those schools for which we have attendance data for grades 2 through 5 in 2003. These data are complete for 13 schools (12 from our original sample of 19 and 1 school which was established in 2003). Since this sample is not conditional on availability of data for 2002, it is larger (number of students being 1791) than that in Table 3, column 1. Grade level estimates based on equation 1 are in Table 4. The average treatment effect is 4.1 percentage points in column 1. This is marginally higher, but close to the effect we see for the 19 schools and for the student panel in Table 3. It suggests that there could be significant grade-wise variations in the treatment effect. Indeed, in subsequent columns in Table 4, when we break up the sample by each grade, we find a steady decline in the treatment effect, with the highest effect of 7.2 percentage points observed for grade 2. By grade 5 this effect disappears. This suggests that younger children were most attracted by the cooked meals being offered in the schools.

Next, we analyze the results by gender in Table 5 . We find a positive effect of the meals only for girls when we compare the coefficient on 'Treat x Sep' in columns 1 and 2. This gender effect, however, might be influenced by the timing of the schools. Most MCD schools run in two shifts - morning and afternoon. While almost all 'boys only' schools are held during the afternoon shift of schools all 'girls only' schools run in the morning shifts. ${ }^{21}$

To investigate this further we analyze our outcome by the school timings in columns 3 and

\footnotetext{
${ }^{21}$ The morning shift (girls only and coeducational) schools are held from 8.00 (7.00) a.m. to 1:00 (12:00) pm while the afternoon shift begins at 1.00 p.m and ends at 6 p.m.
} 
4. As expected, the significant effect of program transition occurs only in the morning schools as indicated by the coefficient on the DID term in columns 3 and 4 . In the last column we restrict the sample to schools that operate in the morning shift and interact the DID term with gender (Boy x Treat x Sep) for these schools. There appears to be no systematic difference in the impact of the meal on the attendance of boys and girls in the treated schools given the insignificant coefficient on the triple interaction term. These coefficients are however difficult to estimate precisely given our small sample of boys in morning schools. We have a total sample of 303 boys, of which 116 are in the treated schools. We can tentatively say that the observed gender effects seem at least in part, simply related to school shift and meal times. It is possible that a meal served in the late afternoon, around 3.00 PM, is less attractive than one served in the middle of the morning, around 10.30 AM. Since the morning shift classes begin very early in the day, students may not be able to have food at home before coming to school unlike students in the afternoon shifts. This was the initial rationale behind the school breakfast program in the U.S (FRAC, 2003). Our results suggest that the timing of the meals can be an important aspect of program design. ${ }^{22}$

\section{Type of school meal menu}

Next, we combine attendance data with the information on menus obtained from the school meal records to analyze the effect of the type of school menu on students' attendance rates.

When the cooked meals were first introduced in 2003, the MCD listed 16 permissible menus. These included very simple and relatively cheap menus such as sweet and salty porridge as well as more elaborate ones, which combined rice or wheat bread with vegetables and pulses.

\footnotetext{
${ }^{22}$ We conducted the following robustness checks of our results. First, we restrict the data to our most parsimonious sample of 12 schools (excluding the one school which was established only in 2003) for which we have complete information. The results of this are shown in Table A3 in the Appendix. We find that our results hold up to some extent and the largest impact is seen in grade 2. The impacts on the other grades are insignificant or weakly significant. Second, for all our estimates we report standard errors clustered at the student level. Although our treatment was at the school level, given the small number of schools in our sample clustering standard errors at that level could bias our results. In Table A4, we report program estimates and standard errors (for Treat x Sep) for our 3 main results using the sample of 19 (Panel 1), the student panel of 16 (Panel 2) and the restricted sample of 13 (Panel 3) schools. Column 1 recaps the results reported in the main text. Columns 2 to 6 show the estimates for different specifications and corrections of standard errors. The magnitudes of the estimates are unchanged whether we use child (column1), school (column 2) or school-grade (column 3) fixed effects. However, clustering at the school level increases the standard errors (column 4). The standard errors after the Moulton correction are shown in columns 5 and 6 (Angrist and Pischke, 2008). Except in column (4) and Panels 1 and 2 in column (6), our estimates remain significant across all specifications.
} 
Besides greater variety, the two item menus (rice/wheat with vegetables/pulses) may have held greater attraction for students because they were more appetizing. Some schools continued to serve the ready-to-eat snacks on a few days. We find that two-item menus were provided about $22 \%$ of school days in the 30 days after starting cooked meals. ${ }^{23}$ Moreover, there are significant differences across schools in the percentage of days two-menu items were served. Unfortunately, we do not have detailed information on the schools' providers during the period of transition in the meal program but we conjecture that variation in providers' capacity, physical infrastructure and financial ability may have been some of the key determinants of the type and frequency of school meal menu served. By December 2003, all of our sampled schools had transitioned to serving cooked meals.

The school records that contain information on the menu served on each school day were available for 14 of our 19 schools. This restricts our sample to these 14 schools for the analysis of the impact of menu type on attendance rates. Table A5 in the Appendix compares the ward and school characteristics of two groups of schools - those that served two item menus more and less often than the median percentage of school days two item menus were served in the sample. We find insignificant differences in the observable characteristics of these two groups of schools by the frequency of the two item menus served.

To identify the impact of menu type we first compare the change in attendance rates of schools that transitioned to serving multiple item menus more frequently between April and December, 2003 to those schools which served them less frequently using equation 1 . We define as 'treatment' group (i.e. Treat $_{j}=1$ ) those schools where two-item menus were served greater than the median proportion of school days in the full sample and as 'control' group those where less than the proportion of median number of days two item menus were served. In this analysis, $m=1$ if the month is December 2003. Our comparison month is again April 2003. In Table 6, column 1, the coefficient on Treat $_{j}$ x Dec suggests that the attendance rate was higher by 2.3 percentage points when two items are served more frequently. ${ }^{24}$

However, not only is our sample size small, it is quite likely that the two groups of schools

\footnotetext{
${ }^{23}$ On average, schools served a one item meal on $73 \%$ and ready-to-eat snacks on $2 \%$ of school days in a month. There was no distribution of meals on the remaining $3 \%$ of school days.

${ }^{24}$ Our results for meal type are qualitatively unchanged if we compare attendance rates between April and September 2003 by interacting 'cooked x two item x september', where 'cooked' is a dummy for Phase 1 school and 'two item' is the dummy for two item menus served more than the median number of school days. This result is available on request.
} 
had different unobservable characteristics that may have affected the type or frequency of menu adoption as well as student participation rates. Unlike the previous analysis, we cannot compare the change in attendance of pre-treatment years to validate our results as we do not have attendance data for December 2002. Instead we adopt a 2SLS approach to check the robustness of our OLS estimate of the effect of menu variety. Our instrument for a school's frequency in serving two-item menus is the distance of the school from its own provider in 2003. Most MCD schools are located in densely populated colonies and slums (De et al., 2005). Meal providers that were located closer to the schools they were serving were more likely to have smaller kitchens and poorer infrastructure. In contrast, those located on the outskirts of Delhi were likely to have larger kitchens and improved infrastructure, including the possibility of introducing automation, as it happened post $2005 .{ }^{25}$ The latter providers may have had better capacity to provide two item menus. As discussed earlier, the MCD invited private parties to express interest in providing cooked meals in January 2003. The schools did not have a say in which provider would serve them school meals. This decision was made by the MCD (Directorate of Education, Delhi, Mid-Day Meal Cell). Therefore, the distance of the school from its provider should be exogenous to the characteristics of the school. In Table A6 in the Appendix, we compare the school level characteristics of schools located more than $5 \mathrm{kms}$ (which was the average distance of a school from its provider in our sample) and those located less than $5 \mathrm{kms}$. from their meal provider in 2003. We find that they are comparable on all observables. This suggests that our claim on exogeneity of meal provider is valid.

In column 2, bottom panel (First Stage) of Table 6, the coefficient on the instrument in the first stage suggests that if the meal provider was located further away from the school, the school was more likely to get two item menus. The Cragg-Donald weak identification test indicates that our first stage is well identified. The second stage coefficient on Treat $_{j} \mathrm{x}$ Dec reported in the top panel of column 2 suggest that the attendance rate was almost 16.7 percentage points higher in schools serving two item menus more frequently in December, 2003. The magnitude of the point estimate, however, is considerably larger than the one obtained from the OLS specification in column 1. This may be due to attenuation bias in the OLS estimate due to measurement error in the frequency of type of menu served. Nevertheless, the significant estimates across all columns gives us confidence in concluding that the type of menu served did have a significant impact of students' attendance rates.

\footnotetext{
${ }^{25}$ Post the stringent quality checks by the MCD, in 2005 providers introduced semi-automation in their kitchens and served, almost on all school days, multiple item menus.
} 
Effect of transition to cooked meals on enrolment

Our data are not well suited to studying enrolment changes in response to the program because we do not have aggregate, monthly enrolment figures for our sample of schools. However, the school meal records that we use to assess menu variety also contained the daily, grade level enrolment figures. For 13 of the 14 schools for which we obtained the school meal records, we were able to obtain the daily enrolment in every grade for a calendar month before and after cooked meals were introduced. The actual number of school days (and months) for which we could obtain this information varied for each school depending on the date of introduction of school meals and number of holidays in a month. The minimum number of days for which we have enrolment when ready-to-eat snacks were provided is 12 days while the number of days after cooked meals is 15. Furthermore, since MCD schools enrol students until the end of August of each academic year, we cannot expect to see any increase in enrolment for schools that transitioned to cooked meals in Phase 2 (i.e. schools which introduced cooked meals after September 2003). However, we can compare enrolment in each grade immediately before and after the transition to the cooked meal in Phase 1 schools as these were the schools that continued to enrol students after the transition to cooked meals. Of the 13 schools for which we obtained enrolment data, 5 were Phase 1 schools. Unlike the attendance analysis, we utilize enrolment data for grade 1 as well as grades 2 through 5 .

We estimate the following school- fixed effects specification for Phase 1 schools:

$$
E_{c j d}=\delta_{0}+\delta_{1} \text { Treat }_{j d}+\phi_{j}+v_{c j d}
$$

where $E_{c j d}$ is the number of students enrolled in grade $c$ in school $j$ on school day $d$. Treat $t_{j d}$ takes value 1 for all school days after cooked meals were introduced and 0 before. $\phi_{j}$ is the school-fixed effects. The coefficient of interest is $\delta_{1}$ which gives the change in enrolment after cooked meals. Since we do not have a control group of schools, i.e. enrolment data for schools which had not introduced cooked meals for the same days, we are able to estimate only a single difference model. We first estimate this equation pooling all grades and, then, separately for each grade.

Table 7 shows the results of equation 2. Column (1) shows the estimate for all grades. Subsequent columns show the estimates for each grade separately. Our results tentatively suggest 
that enrolment increased by 6.83 students on average after cooked meals were introduced. The highest effect was seen in grade 1 where enrolment increased by more than 27 students. The effect diminishes monotonically by grade and we see no effect on grades 4 and 5. Our results, though suggestive, indicate that the program transition attracted younger children to schools more than older ones. This result supports are earlier finding for student attendance rates.

\section{Conclusion}

In this study, public primary schools in Delhi transitioned from an on-site program of providing packaged, ready-to-eat snacks such as biscuits to serving cooked meals to all enrolled students in the 2003-04 academic year. This transition was rolled out in two phases over a period of five months in schools managed by the Municipal Corporation of Delhi (MCD). We use this staggered implementation of the program across MCD schools to identify transition impacts, comparing the attendance rates of students of grades 2 to 5 in schools that transitioned to cooked meals first to those that transitioned later in the year from ready-to-eat snacks. ${ }^{26}$

The main objective of this paper was to examine whether cost neutral changes in the design of a school feeding program could have substantial impact on student participation rates. We found that it did, especially for lower grades. Our work also suggests that greater attention to the timing of the meal and the menu served could be a cheap and effective way of raising primary school attendance rates. These results are robust to potential differences in school specific trends as well as endogeneity in the type of meals served. The nature of our data did not allow us to say very much on enrolment and we have no direct measures of child health. We hope to address some of these questions in future work.

Our results align with the previous literature on the effects of school subsidy programs, and in particular schools meals, on participation rates of students. However, unlike these existing studies we explore the effects of a change in program design and the heterogeneity in program transition impact. Serving cooked meals during school hours may have raised incentives for the beneficiaries to attend school more regularly due to one or more factors related to program

\footnotetext{
${ }^{26}$ See Table A7 in the Appendix for a description of the school samples and the estimation methods used to analyze the attendance outcome.
} 
design. First, the less portable cooked meals may have improved targeting by limiting redistribution of the transfer from the child at home. This may have increased the attractiveness of school attendance by the child. Second, the increased regularity in the provision of cooked meals relative to the ready-to-eat snacks may have raised the value of the school transfer for the beneficiary households. Finally, a hot meal may have been more attractive than the biscuits that were usually provided under the earlier regime. Our findings are pertinent given that the transition to cooked meals and then to their improved and regulated quality of meals in Delhi, is yet to be completed in most of India. Moreover, our results demonstrate that even in our context, where initial attendance rates were high relative to the national average, changes in the design of school transfer programs had a significant impact on daily participation rates. These findings, therefore, are a lower bound on the potential impact of cost-neutral changes in

program design on school participation in developing countries which often exhibit low levels of school attendance and enrolment.

There are two main policy implications of the results in this paper. First, school subsidies can be an important policy instrument for making regular schooling more desirable. Second, our findings illustrate the need for greater attention to the design and quality of transfer programs in order to yield higher returns within constrained budgets.

\section{References}

Adelman, Sarah, Daniel Gilligan, and Kim Lehrer (2008) 'How effective are food for education programs?: A critical assessment of the evidence from developing countries.' Food Policy Review Vol. 9, International Food Policy Research Institute.

Afridi, Farzana (2010) 'Child welfare programs and child nutrition: Evidence from a mandated school meal program in India.' Journal of Development Economics 92(2), 152-165.

_ (2011) 'The impact of school meals on school participation: Evidence from rural India.' Journal of Development Studies 47(11), 1636-1656.

Ahmed, Akhter U (2004) 'Impact of feeding children in school: Evidence from Bangladesh.' International Food Policy Research Institute, unpublished report.

Ahmed, Akhter U, and Carlo Del Ninno (2002) 'Food for education program in Bangladesh: 
An evaluation of its impact on educational attainment and food security.' International Food Policy Research Institute, Food Consumption and Nutrition Division, discussion paper.

Alderman, Harold, Daniel O Gilligan, and Kim Lehrer (2012) 'The impact of food for education programs on school participation in northern Uganda.' Economic Development and Cultural Change 61(1), 187-218.

Angrist, Joshua D, and Jörn-Steffen Pischke (2008) Mostly Harmless Econometrics: An Empiricist's Companion (Princeton University Press)

Behrman, Jere R, Piyali Sengupta, and Petra Todd (2005) 'Progressing through PROGRESA: An impact assessment of a school subsidy experiment in rural Mexico.' Economic Development and Cultural Change 54(1), 237-275.

De, Anuradha, Claire Noronha, and Meera Samson (2005) 'Towards more benefits from Delhi's midday meal scheme.' Technical Report, Collaborative Research and Dissemination, New Delhi.

Directorate of Education, Delhi (Mid-Day Meal Cell) (2006) 'Note regarding implementation of mid-day-meal schemes in Delhi.'

Dreze, Jean, and Aparajita Goyal (2003) 'Future of mid-day meals.' Economic and Political Weekly pp. 4673-4683.

Educational Consultants India Limited (2007) 'Study of student's attendance in primary and upper primary schools.' Technical Report, Research, Evaluation and Studies Unit, Sarva Shiksha Abhiyan.

Evans, David, Michael Kremer, and Muthoni Ngatia (2008) 'The impact of distributing school uniforms on children's education in Kenya.' World Bank, mimeo.

FRAC (2003) 'School breakfast score card: 2003.' Food Research and Action Centre, Washington D.C.

Glewwe, Paul, and Michael Kremer (2006) 'Schools, teachers, and education outcomes in developing countries.' Handbook of Education Economics 2, 945-1017.

Government of India (2013) 'Education statistics at a glance.' Ministry of Human Resource Development. 
Jayaraman, Rajshri, and Dora Simroth (2015) 'The impact of school lunches on primary school enrollment: Evidence from India's midday meal scheme.' The Scandinavian Journal of Economics. 117(4), 1176-1203.

Kazianga, Harounan, Damien De Walque, and Harold Alderman (2012) 'Educational and child labour impacts of two food-for-education schemes: Evidence from a randomised trial in rural Burkina Faso.' Journal of African Economies 21(5), 723-760.

Khera, Reetika (2006) 'Mid-day meals in primary schools: Achievements and challenges.' Economic and Political Weekly pp. 4742-4750.

_ (2013) 'Mid-day meals: Looking ahead.' Economic and Political Weekly 48(32), 13.

Kremer, Michael, Edward Miguel, and Rebecca Thornton (2009) 'Incentives to learn.' The Review of Economics and Statistics 91(3), 437-456.

Kremer, Michael, Sylvie Moulin, and Robert Namunyu (2002) 'Unbalanced decentralization.' Harvard University. Cambridge, MA. Available on line at http://econ. bu. edu/dilipm/40kremounam. pdf. Processed.

Ravallion, Martin, and Quentin Wodon (2000) 'Does child labour displace schooling? Evidence on behavioural responses to an enrollment subsidy.' The Economic Journal 110(462), 158-175.

Schultz, T Paul (2004) 'School subsidies for the poor: Evaluating the Mexican Progresa poverty program.' Journal of Development Economics 74(1), 199-250.

Sharma, Sushma, Santosh Jain Passi, Salila Thomas, and Hema S Gopalan (2006) 'Evaluation of mid day meal programme in MCD schools.' Nutrition Foundation of India, Scientific Report 18.

Singh, Abhijeet, Albert Park, and Stefan Dercon (2014) 'School meals as a safety net: An evaluation of the midday meal scheme in India.' Economic Development and Cultural Change 62(2), 275-306.

Vermeersch, Christel, and Michael Kremer (2005) 'School meals, educational achievement, and school competition: Evidence from a randomized evaluation.' World Bank, working paper number 3523

World Food Programme (2013) 'State of school feeding worldwide 2013.' Rome, Italy 
Table 1: Summary Statistics by Treatment Status

\begin{tabular}{lccc}
\hline \hline & $\begin{array}{c}\text { Control } \\
\text { Characteristics }\end{array}$ & $\begin{array}{c}\text { Treatment } \\
(\mathbf{N}=\mathbf{9})\end{array}$ & Difference \\
\cline { 2 - 4 } Ward-level & $(1)$ & $(2)$ & $(2)-(1)$ \\
Total literacy & 0.81 & 0.77 & -0.035 \\
& $(0.007)$ & $(0.026)$ & $(0.026)$ \\
Male literacy & 0.87 & 0.85 & -0.023 \\
& $(0.002)$ & $(0.016)$ & $(0.016)$ \\
Female literacy & 0.72 & 0.66 & -0.061 \\
& $(0.016)$ & $(0.048)$ & $(0.048)$ \\
Scheduled caste & 0.12 & 0.14 & 0.02 \\
& $(0.021)$ & $(0.030)$ & $(0.036)$ \\
\cline { 2 - 4 } School-level & & & \\
Monthly attendance rate in April & 0.80 & 0.78 & -0.02 \\
& $(0.028)$ & $(0.020)$ & $(0.035)$ \\
Distance from own provider (kms) & 4.44 & 4.71 & 0.27 \\
& $(1.22)$ & $(1.41)$ & $(1.86)$ \\
Drinking water & 0.89 & 1 & 0.11 \\
& $(0.111)$ & $(0)$ & $(0.111)$ \\
Free text books & 1 & 1 & \\
Free uniform & 1 & 1 & \\
Library & 0.89 & 0.89 & \\
& $(0.111)$ & $(0.111)$ & \\
Parent-teacher association & 1 & 1 & \\
Playground & 1 & 1 & \\
Toilets & 1 & 1 & \\
Ratio of Temporary & 0.01 & 0.21 & 0.20 \\
to Permanent teachers & $(0.007)$ & $(0.14)$ & $(0.14)$ \\
\hline \hline
\end{tabular}

Notes: Ward level data from Primary Census Abstract of India, 2001; school level data for 2003 from retrospective survey. Average school level attendance was calculated keeping all students of all grades for which attendance records for April 2003 were available, excluding grade 1. Data missing for 1 school in the control group. Standard errors in parentheses. Significance levels *** 1\%** 5\%* $10 \%$. 
Table 2: Change in April-September Monthly Attendance Rates, by Treatment Status

\begin{tabular}{lccc}
\hline \hline \multirow{2}{*}{ Change } & Control & Treatment & Difference \\
\hline \multirow{3}{*}{ (A) $\Delta 2002$} & & $(1)$ & $(2)-(1)$ \\
\cline { 2 - 4 } April 2002 & 0.06 & 0.06 & 0 \\
& $0.008)$ & $(0.010)$ & $(0.013)$ \\
& $(0.073)$ & 0.79 & \\
\hline B) $\Delta$ 2003 & 0.07 & 0.11 & $0.04^{* * *}$ \\
April 2003 & $(0.008)$ & $(0.009)$ & $(0.012)$ \\
& 0.80 & 0.78 & \\
\hline Difference (B)-(A) & $(0.086)$ & $(0.063)$ & \\
& 0.01 & $0.05^{* * *}$ & $0.04^{* * *}$ \\
\hline \hline
\end{tabular}

Notes: The sample is the repeated cross-section of grades of 19 schools (10 control and 9 treatment) for which attendance data were obtained for years 2002 and 2003. Average attendance rates are calculated by averaging over all enrolled students, excluding grade 1 , in the respective months. Standard errors in parentheses. Significance levels $* * * 1 \% * * 5 \% * 10 \%$. 
Table 3: Effect of Cooked Meals on Monthly Attendance Rate (Student Fixed Effects)

\begin{tabular}{lcccc}
\hline \hline \multirow{2}{*}{ Variables } & \multicolumn{4}{c}{ Attendance in year } \\
\hline \multirow{2}{*}{ Treat x Sep } & $\mathbf{2 0 0 3}$ & $\mathbf{2 0 0 2}$ & $\mathbf{2 0 0 3}$ & $\mathbf{2 0 0 2}$ \\
\cline { 2 - 5 } & $0.027^{* *}$ & 0.006 & $0.031^{*}$ & 0.007 \\
Sep & $(0.012)$ & $(0.011)$ & $(0.016)$ & $(0.015)$ \\
& $0.073^{* * *}$ & $0.047^{* * *}$ & $0.081^{* * *}$ & $0.066^{* * *}$ \\
Constant & $(0.008)$ & $(0.007)$ & $(0.012)$ & $(0.009)$ \\
& $0.816^{* * *}$ & $0.844^{* * *}$ & $0.815^{* * *}$ & $0.845^{* * *}$ \\
\hline Obs & $(0.003)$ & $(0.003)$ & $(0.004)$ & $(0.004)$ \\
No. of schools & 3182 & 3128 & 1654 & 1654 \\
No. of students & 19 & 19 & 16 & 16 \\
$R^{2}$ & 0.121 & 0.047 & 0.149 & 0.094 \\
\hline \hline
\end{tabular}

Notes: The sample in columns 1 and 2 is restricted to the repeated cross section of grades of the 19 schools for which attendance records were available for 2002 and 2003. Column 1 shows the estimates for the cohort of 2003 while column 2 does the same for cohort of 2002. Columns 3 and 4 show the estimates in 2003 and 2002 respectively for the panel of 827 students who were present from April 2002 to September 2003. These 827 students were from 16 of the 19 schools. Standard errors clustered at student-level in parentheses. Significance levels ${ }^{* * *} 1 \% * * 5 \% * 10 \%$. 
Table 4: Effect of School Meals on Monthly Attendance Rate by Grade (Student Fixed Effects)

\begin{tabular}{lccccc}
\hline \hline \multirow{2}{*}{ Variables } & \multicolumn{5}{c}{ Grades } \\
\hline \multirow{3}{*}{ Treat x Sep } & $\mathbf{2}$ to $\mathbf{5}$ & $\mathbf{2}$ & $\mathbf{3}$ & $\mathbf{4}$ & $\mathbf{5}$ \\
\cline { 2 - 6 } & $(1)$ & $(2)$ & $(3)$ & $(4)$ & $(5)$ \\
Sep & $\left(0.041^{* * *}\right.$ & $0.072^{* * *}$ & $0.044^{* *}$ & $0.040^{* *}$ & 0.013 \\
& $0.047^{* * *}$ & $(0.023)$ & $(0.020)$ & $(0.020)$ & $(0.023)$ \\
Constant & $(0.007)$ & $(0.014)$ & $(0.014)$ & $(0.015)$ & $(0.016)$ \\
& $0.841^{* * *}$ & $0.841^{* * *}$ & $0.846^{* * *}$ & $0.848^{* * *}$ & $0.830^{* * *}$ \\
\hline Obs & $(0.003)$ & $(0.006)$ & $(0.005)$ & $(0.005)$ & $(0.006)$ \\
No. of schools & 3582 & 878 & 952 & 912 & 842 \\
No. of students & 13 & 13 & 13 & 13 & 13 \\
$R^{2}$ & 0.087 & 0.055 & 0.072 & 0.086 & 0.174 \\
\hline \hline
\end{tabular}

Notes: The sample uses students enrolled in April and September of 2003 from 13 schools for which we could obtain attendance records of that year for grades 2 to 5. Standard errors clustered at student-level in parentheses. Significance levels *** $1 \% * * 5 \% * 10 \%$. 
Table 5: Effect of School Meals on Monthly Attendance Rate by Gender and School Shift (Student Fixed Effects)

\begin{tabular}{lcc|ccc}
\hline \hline \multirow{2}{*}{ Variables } & \multicolumn{2}{c}{ Gender } & \multicolumn{3}{c}{ School shift } \\
\hline \multirow{3}{*}{ Treat x Sep } & Boys & Girls & Afternoon & Morning & Morning \\
\cline { 2 - 6 } & $(1)$ & $(2)$ & $(3)$ & $(4)$ & $(5)$ \\
Sep & -0.007 & $0.020^{*}$ & -0.008 & $0.030^{* * *}$ & $0.020^{*}$ \\
& $(0.019)$ & $(0.011)$ & $(0.025)$ & $(0.011)$ & $(0.011)$ \\
Boy x Treat x Sep & $\left(0.077^{* * *}\right.$ & $0.078^{* * *}$ & $0.111^{* * *}$ & $0.059^{* * *}$ & $0.078^{* * *}$ \\
& & $(0.008)$ & $(0.012)$ & $(0.008)$ & $(0.008)$ \\
Boy x Sep & & & & 0.033 \\
& & & & & $(0.031)$ \\
Constant & & & & & $-0.092^{* * *}$ \\
& $0.823^{* * *}$ & $0.816^{* * *}$ & $0.785^{* * *}$ & $0.830^{* * *}$ & $0.830^{* * *}$ \\
Obs & $(0.004)$ & $(0.003)$ & $(0.005)$ & $(0.003)$ & $(0.003)$ \\
No. of schools & 1696 & 2810 & 1090 & 3416 & 3416 \\
No. of students & 8 & 14 & 5 & 14 & 14 \\
$R^{2}$ & 848 & 1405 & 545 & 1708 & 1708 \\
\hline \hline
\end{tabular}

Notes: The sample consists of 19 schools including 3 schools that enrol both boys and girls. All grades of the 19 schools for which attendance records of 2003 were available are included. Standard errors clustered at student-level in parentheses. Significance levels $* * * 1 \% * * 5 \%$

$* 10 \%$. 
Table 6: Effect of School Meals on Monthly Attendance Rate by Menu Type (Student Fixed Effects)

\begin{tabular}{lcc}
\hline \hline Variables & OLS & 2SLS \\
\hline \multirow{2}{*}{ Treat x Dec } & $(1)$ & $(2)$ \\
\cline { 2 - 3 } Dec & $0.023^{*}$ & $0.167^{*}$ \\
& $(0.01)$ & $(0.09)$ \\
Constant & $0.081^{* * *}$ & 0.006 \\
& $(0.01)$ & $(0.05)$ \\
& $0.827^{* * *}$ & $0.90^{* * *}$ \\
First Stage & $(0.003)$ & $(0.026)$ \\
(IV=Distance from Provider x Dec) & & \\
& & $\left(0.019^{* * *}\right.$ \\
Dec & & $0.436^{* * *}$ \\
& & $(0.019)$ \\
Weak identification test & & \\
(Cragg-Donald Wald F statistic) & & 34.49 \\
\hline Obs & 2962 & 2962 \\
No. of schools & 14 & 14 \\
No. of students & 1481 & 1481 \\
\hline \hline
\end{tabular}

Notes: The variable of interest is Treat which indicates if a school received two-item meals more than the sample median percentage of days of two-item meals. In column 2, the distance of the school from its provider in 2003 is the instrument for 'Treat'. Standard errors clustered at student-level in parentheses. Significance levels *** $1 \%$ ** $5 \% * 10 \%$. 
Table 7: Effect of School Meals on Enrolment Levels (School Fixed Effects)

\begin{tabular}{lcccccc}
\hline \hline \multirow{2}{*}{ Variables } & \multicolumn{7}{c}{ Grades } \\
Treat & $\mathbf{1}$ to $\mathbf{5}$ & $\mathbf{1}$ & $\mathbf{2}$ & $\mathbf{3}$ & $\mathbf{4}$ & $\mathbf{5}$ \\
\cline { 2 - 7 } & $(1)$ & $(2)$ & $(3)$ & $(4)$ & $(5)$ & $(6)$ \\
Constant & $6.83^{* * *}$ & $27.25^{* * *}$ & $3.18^{* * *}$ & $2.73^{* * *}$ & 0.583 & 0.433 \\
& $(1.484)$ & $(3.096)$ & $(0.642)$ & $(0.351)$ & $(0.383)$ & $(0.272)$ \\
& $60.81^{* * *}$ & $32.08^{* * *}$ & $72.000^{* * *}$ & $72.300^{* * *}$ & $76.950^{* * *}$ & $64.367^{* * *}$ \\
No. of schools & $(1.843)$ & $(2.308)$ & $(0.479)$ & $(0.262)$ & $(0.286)$ & $(0.203)$ \\
No. of grade - days & 5 & 5 & 5 & 5 & 5 & 5 \\
$R^{2}$ & 675 & 135 & 135 & 135 & 135 & 135 \\
\hline \hline
\end{tabular}

Notes: The sample is restricted to 5 of the 9 Phase 1 schools for whom enrolment records were obtained. The variable of interest is Treat which takes value 1 for school days when cooked meals were provided and 0 when ready-to-eat snacks were distributed. The dependant variable is the number of students enrolled in a grade. Standard errors clustered at student-level in parentheses. Significance levels $* * * 1 \% * * 5 \% * 10 \%$. 


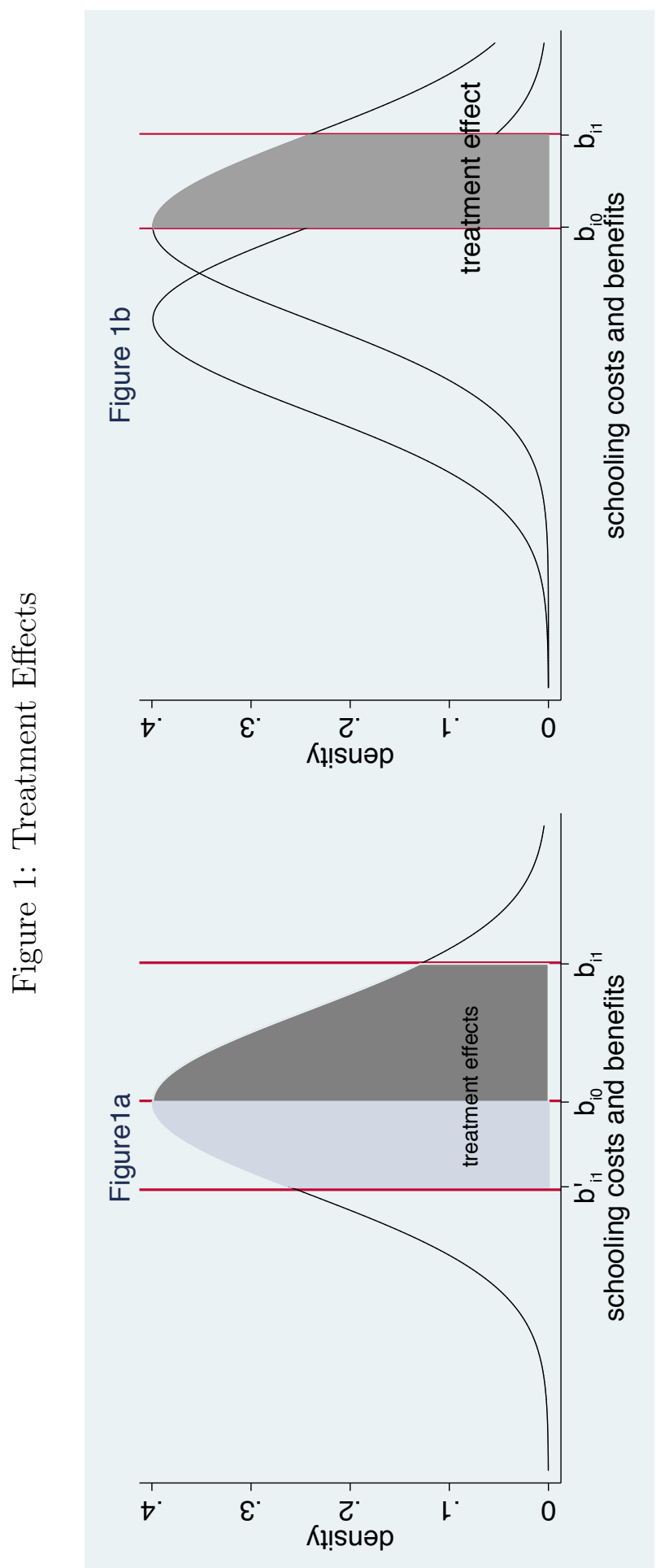




\section{Appendix}

Table A1: Per Child Per Day Cost of the School Meal Program (in Rs.)

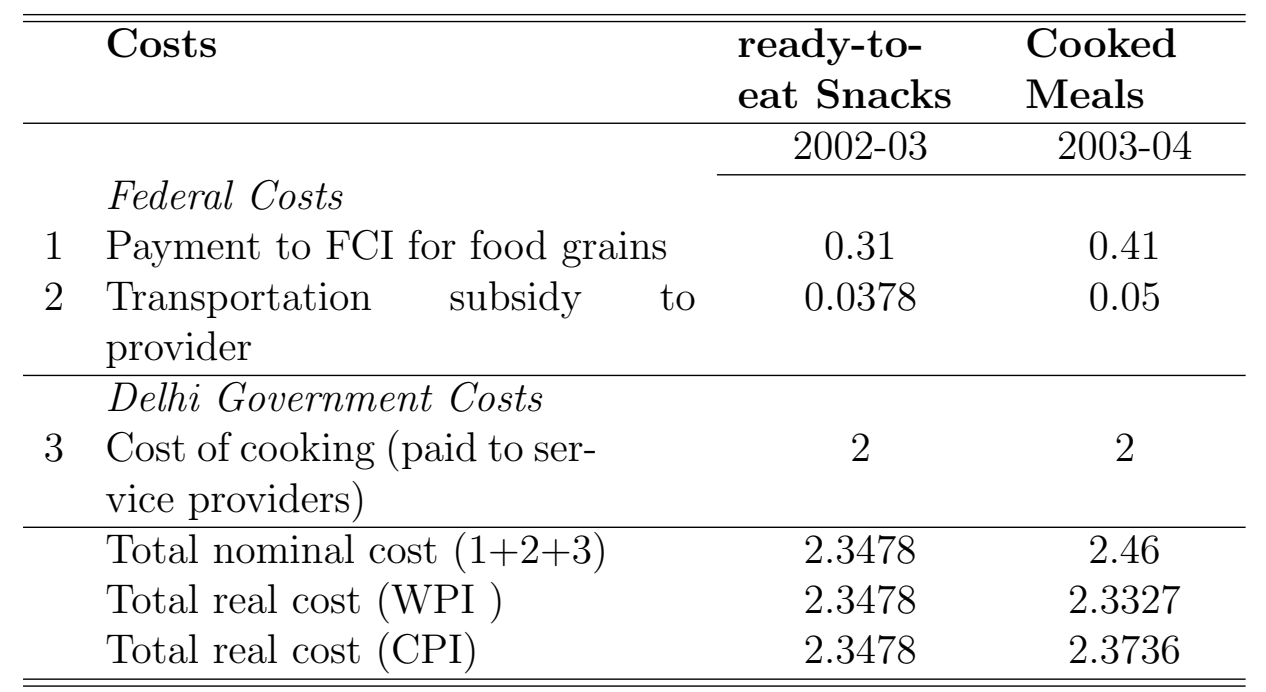

Source: Data obtained via official communications from the Ministry of Human Resource Development (via Letter No- D-186 DDE/MDM(HQ)/11); wholesale and consumer price index for Delhi obtained from the Annual Report of the Planning Commission of Delhi.

Notes: FCI - Food Corporation of India. Transportation subsidy to provider per child per day $=$ Transport subsidy per gram*food grain allocation per child per day. 
Table A2: Average Demographic Characteristics of Sampled Zone and Delhi

\begin{tabular}{lcc}
\hline \hline & Delhi (Urban) & MCD Central Zone \\
\hline Total Literacy & 0.82 & 0.82 \\
Male Literacy & 0.87 & 0.88 \\
Female Literacy & 0.75 & 0.74 \\
Scheduled Caste & 0.17 & 0.16 \\
Occupation of main worker & & \\
Cultivators & 0.002 & 0.002 \\
Agricultural Labor & 0.001 & 0.002 \\
Household Industry & 0.03 & 0.02 \\
Others & 0.97 & 0.98 \\
\hline \hline
\end{tabular}

Notes: Data aggregated from ward level statistics from Census, 2001. Main workers are defined as those who spend the most time in the household working for income. Household industry is defined by the census as a small scale business run by members of the household within its precincts. 
Table A3: Effect of School Meals on Monthly Attendance Rate by Grade (Student Fixed Effects)

\begin{tabular}{|c|c|c|c|c|c|}
\hline \multirow[b]{2}{*}{ Variables } & \multicolumn{5}{|c|}{ Grades } \\
\hline & 2 to 5 & 2 & 3 & 4 & 5 \\
\hline \multirow{3}{*}{ Treat x Sep } & $(1)$ & $(2)$ & $(3)$ & $(4)$ & $(5)$ \\
\hline & $0.030^{* * *}$ & $0.058^{* *}$ & 0.023 & $0.041^{*}$ & 0.003 \\
\hline & $(0.011)$ & $(0.023)$ & $(0.020)$ & $(0.022)$ & $(0.024)$ \\
\hline \multirow[t]{2}{*}{ Sep } & $0.059^{* * *}$ & 0.023 & $0.053^{* * *}$ & $0.043^{* *}$ & $0.112^{* * *}$ \\
\hline & $(0.008)$ & $(0.015)$ & $(0.014)$ & $(0.017)$ & $(0.018)$ \\
\hline \multirow[t]{2}{*}{ Constant } & $0.835^{* * *}$ & $0.832^{* * *}$ & $0.838^{* * *}$ & $0.844^{* * *}$ & $0.822^{* * *}$ \\
\hline & $(0.003)$ & $(0.006)$ & $(0.005)$ & $(0.005)$ & $(0.006)$ \\
\hline Obs & 3360 & 808 & 896 & 854 & 802 \\
\hline No. of schools & 12 & 12 & 12 & 12 & 12 \\
\hline No. of students & 1680 & 404 & 448 & 427 & 401 \\
\hline$R^{2}$ & 0.097 & 0.062 & 0.090 & 0.085 & 0.181 \\
\hline
\end{tabular}

Notes: This table shows the result of estimating equation (1) for the subsample of 12 of 19 schools for which we obtained attendance records of 2003 for all grades. This excludes 1 school that was established in 2003. Standard errors clustered at student-level in parentheses. Significance levels $* * * 1 \% * *$ $5 \% * 10 \%$. 
Table A4: Program Estimates Across Samples and Specifications

\begin{tabular}{lccccc}
\hline \hline & $(1)$ & $(2)$ & $(3)$ & $(4)$ & $(5)$ \\
\hline Panel 1: Repeated cross-section school and & grade & & & \\
Treat x Sep & $0.027^{* *}$ & $0.027^{* *}$ & $0.027^{* *}$ & 0.027 & $0.027^{* *}$ \\
& $(0.0117)$ & $(0.0126)$ & $(0.0124)$ & $(0.0319)$ & $(0.0125)$ \\
No. of students & 1591 & 1591 & 1591 & 1591 & 1591 \\
No. of schools & 19 & 19 & 19 & 19 & 19 \\
\hline Panel 2: Student panel & & & & & \\
Treat x Sep & $0.031^{*}$ & $0.031^{*}$ & $0.031^{*}$ & 0.031 & $0.031^{*}$ \\
& $(0.0163)$ & $(0.0168)$ & $(0.0166)$ & $(0.0372)$ & $(0.0168)$ \\
No. of students & 827 & 827 & 827 & 827 & 827 \\
No. of schools & 16 & 16 & 16 & 16 & 16 \\
\hline Panel 3: Grade sample & & & & & \\
Treat x Sep & $0.041^{* * *}$ & $0.041^{* * *}$ & $0.041^{* * *}$ & 0.041 & $0.041^{* * *}$ \\
& $(0.0109)$ & $(0.0114)$ & $(0.0113)$ & $(0.0362)$ & $(0.0115)$ \\
No. of students & 1791 & 1791 & 1791 & 1791 & 1791 \\
No. of schools & 13 & 13 & 13 & 13 & 13 \\
\hline FE & Student & School & School-Grade & Student & School \\
Standard error correction & Het. Robust & Het. Robust & Het. Robust & Clustered Moulton \\
& & & & School & Adjusted \\
\hline \hline
\end{tabular}

Notes: Panel 1- repeated cross-section of school-grade in 2003 and 2002; Panel 2 - panel of students who were enrolled from April 2002 to September 2003; Panel 3 - sample of schools with complete grade attendance records in 2003. Significance levels $* * * 1 \% * * 5 \% * 10 \%$. 
Table A5: School Summary Statistics by Frequency of Two-item Menu in Dec 2003

\begin{tabular}{|c|c|c|c|}
\hline \multirow[b]{2}{*}{ Characteristics } & \multicolumn{2}{|c|}{$\begin{array}{l}\% \text { of days two item menus served } \\
\end{array}$} & \multirow[b]{2}{*}{ Difference } \\
\hline & $\begin{array}{l}\text { Less than median } \\
\qquad(\mathrm{N}=6)\end{array}$ & $\begin{array}{c}\text { Greater than median } \\
\qquad(\mathrm{N}=8)\end{array}$ & \\
\hline & $(1)$ & $(2)$ & $(2)-(1)$ \\
\hline \multicolumn{4}{|l|}{ Ward level } \\
\hline Total Literacy & $\begin{array}{c}0.81 \\
(0.008)\end{array}$ & $\begin{array}{c}0.79 \\
(0.027)\end{array}$ & $\begin{array}{c}-0.02 \\
(0.032)\end{array}$ \\
\hline Male Literacy & $\begin{array}{c}0.88 \\
(0.004)\end{array}$ & $\begin{array}{c}0.86 \\
(0.016)\end{array}$ & $\begin{array}{l}-0.02 \\
(0.019)\end{array}$ \\
\hline Female Literacy & $\begin{array}{c}0.73 \\
(0.019)\end{array}$ & $\begin{array}{c}0.70 \\
(0.049)\end{array}$ & $\begin{array}{l}-0.03 \\
(0.059)\end{array}$ \\
\hline Scheduled Caste & $\begin{array}{c}0.11 \\
(0.028)\end{array}$ & $\begin{array}{c}0.13 \\
(0.032)\end{array}$ & $\begin{array}{c}0.03 \\
(0.045)\end{array}$ \\
\hline School level & & & \\
\hline Monthly Attendance Rate in April & $\begin{array}{c}0.81 \\
(0.029)\end{array}$ & $\begin{array}{c}0.79 \\
(0.029)\end{array}$ & $\begin{array}{c}-0.02 \\
(0.042)\end{array}$ \\
\hline Distance from own provider & $\begin{array}{l}4.43 \\
(1.83)\end{array}$ & $\begin{array}{c}4.86 \\
(1.50)\end{array}$ & $\begin{array}{l}0.79 \\
(2.34)\end{array}$ \\
\hline Drinking Water & $\begin{array}{l}0.8 \\
(0.2)\end{array}$ & $\begin{array}{c}1 \\
(0)\end{array}$ & $\begin{array}{c}0.2 \\
(0.15)\end{array}$ \\
\hline Free Text Books & 1 & 1 & \\
\hline Free Uniform & 1 & 1 & \\
\hline Library & $\begin{array}{c}0.60 \\
(0.24)\end{array}$ & $\begin{array}{c}1 \\
(0)\end{array}$ & $\begin{array}{c}0.40 \\
(0.18)\end{array}$ \\
\hline Parent-Teacher Association & 1 & 1 & \\
\hline Playground & 1 & 1 & \\
\hline Toilets & 1 & 1 & \\
\hline $\begin{array}{l}\text { Ratio of Temporary } \\
\text { to Permanent Teachers }\end{array}$ & $\begin{array}{c}0.01 \\
(0.012)\end{array}$ & $\begin{array}{c}0.07 \\
(0.05)\end{array}$ & $\begin{array}{c}0.06 \\
(0.07)\end{array}$ \\
\hline
\end{tabular}

Notes: Ward level data from Primary Census Abstract of India, 2001. School level attendance calculated for all students of all grades for which attendance records for April 2003 were available, excluding grade 1. School data missing for 1 school in column 2. Standard errors in parentheses. Significance levels ${ }^{* * *} 1 \% * * 5 \% * 10 \%$. 
Table A6: Summary Statistics by Distance from Provider in 2003

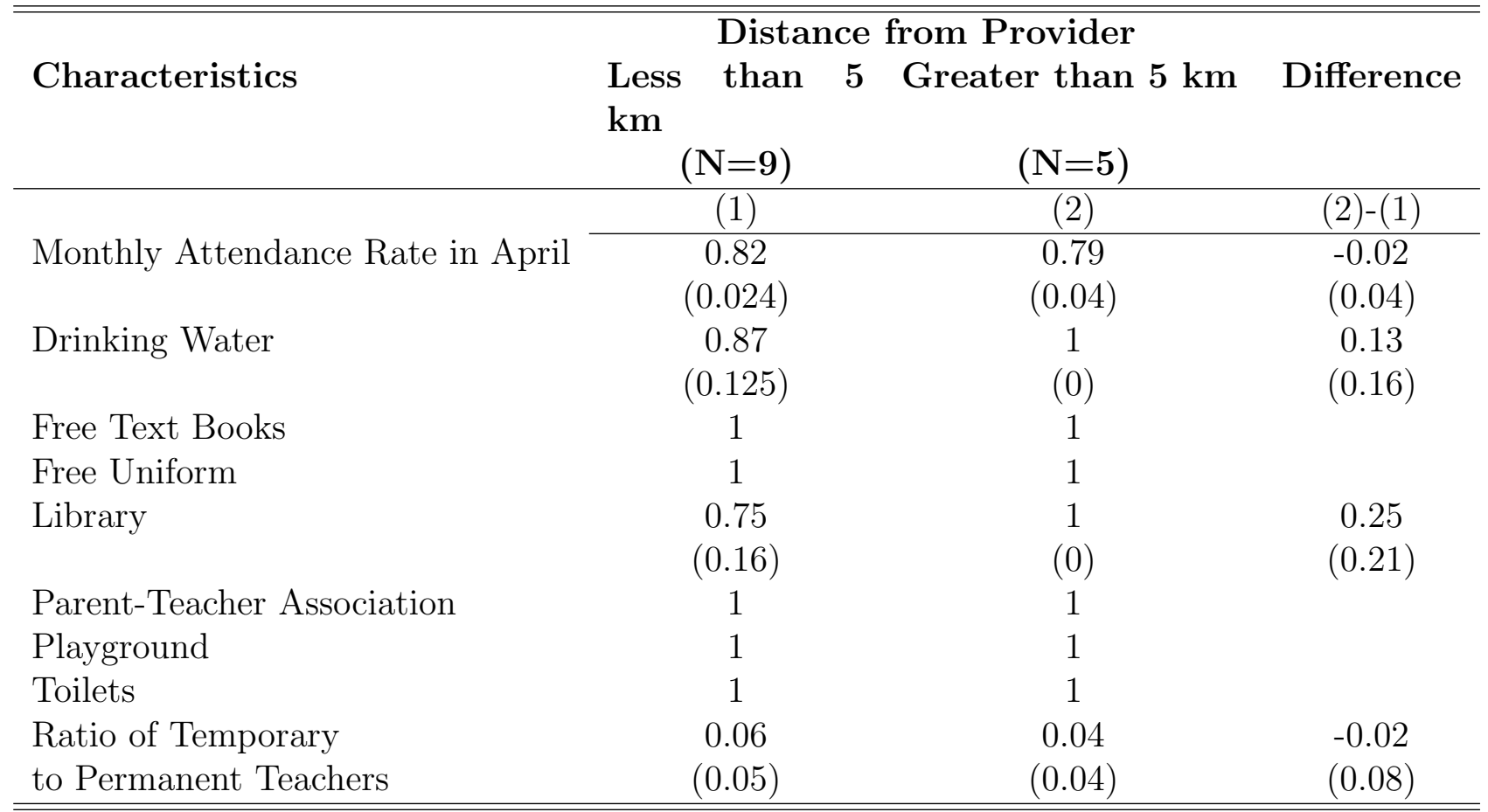

Notes: School level attendance calculated for all students of all grades for which attendance records for April 2003 were available, excluding grade 1. School data missing for 1 school in column 1. Standard errors in parentheses. Significance levels $* * * 1 \% * * 5 \% * 10 \%$. 


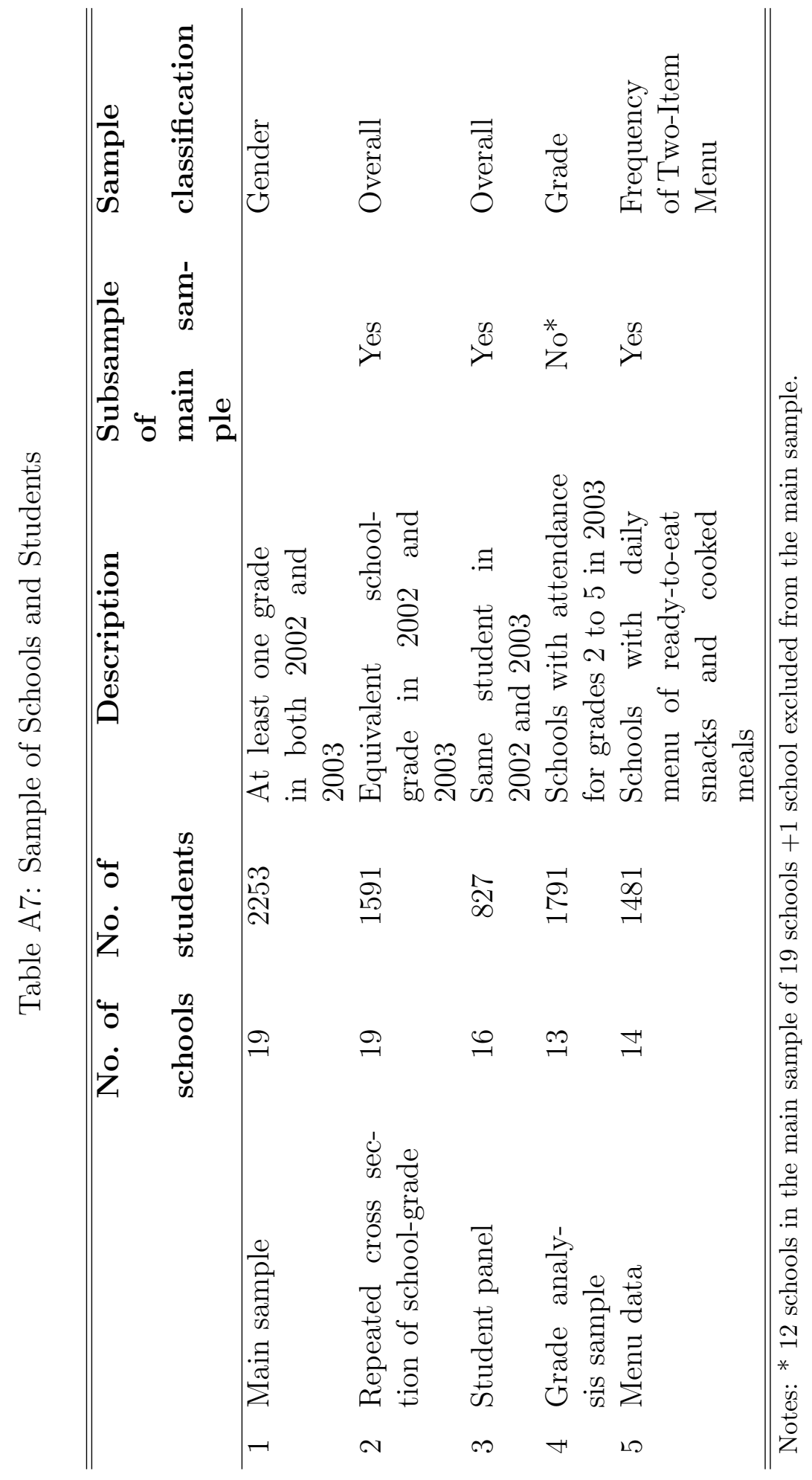


Figure A1: Map of the central zone of Delhi indicating sampled schools

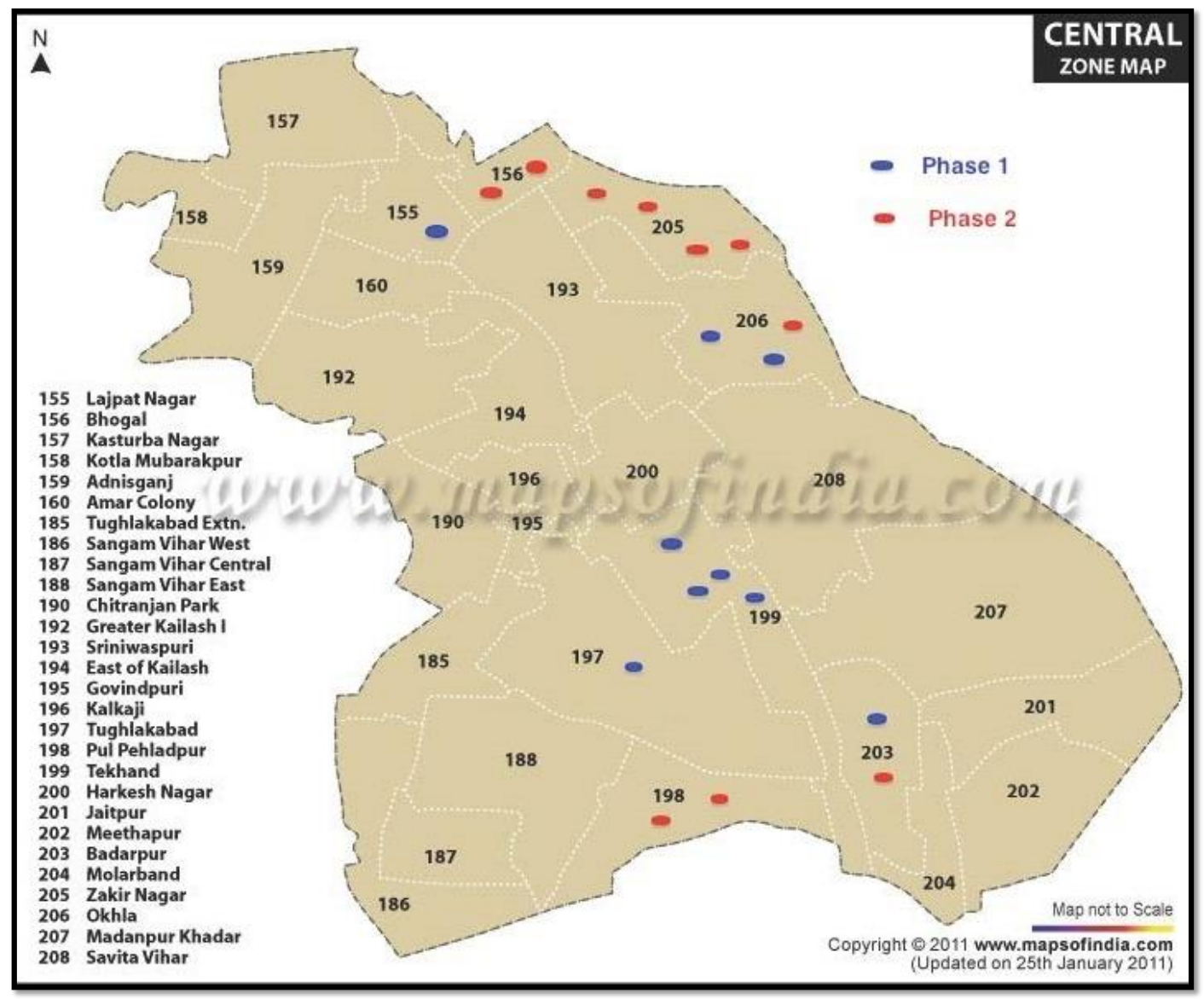

Notes: This figure shows the census wards in which the sampled 19 schools are located. The name and number of the ward is displayed on the left. 